\title{
EL DESCUBRIMIENTO DE LA FAUNA EXÓTICA EN LOS RELATOS DE VIAJES: DE LAS DESCRIPCIONES MEDIEVALES A LAS IMITACIONES EN LA NOVELA HISTÓRICA CONTEMPORÁNEA
}

\author{
KAROLINA ZYGMUNT \\ Universitat de València
}

\begin{abstract}
RESUMEN
El objetivo de este artículo es analizar los rasgos fundamentales de la descripción medieval de algunos animales exóticos y compararla con la descripción de estos mismos animales en la novela histórica. Del cotejo entre textos medievales y actuales se intentará extraer conclusiones en torno al aprovechamiento, a modo de herramientas, que hacen los escritores contemporáneos al mimetizar casi literalmente esas descripciones medievalizantes de animales exóticos. Su objetivo sería obligar al lector moderno a tomar una posición de lectura, produciendo efectos de identificación (con la poética del relato medieval) y a la vez distanciamiento (respecto a las formas narrativas actuales).

PALABRAS ClAVE: animales exóticos, bestiario, descriptio, relatos medievales de viaje, novela histórica.
\end{abstract}

\begin{abstract}
The aim of this article is to discuss the fundamental characteristics of the medieval description of several exotic animals, and to compare it with descriptions of these animals in the contemporary historical novel. From the comparison between medieval and contemporary works, conclusions about the tools used by contemporary writers will be extracted. In particular, it will be shown how they benefit from the imitation, almost literal, of the medieval-style descriptions of exotic animals. The intention of this method, would be to constrain the modern reader to a reading perspective, by producing identification effects (with the medieval poetics) as well as distancing (with respect to the current narrative forms). KEY WORDS: exotic animals, bestiary, descriptio, medieval travel narrative, historical novel
\end{abstract}

\section{LA DESCRIPCIÓN DE LOS ANIMALES EXÓTICOS EN LOS RELATOS MEDIEVALES DE VIAJES}

Hablar de relatos de viajes medievales significa hablar de su gramática interna o de su retórica, es decir, de todos los rasgos discursivos y características genéricas que distinguen este tipo de obras de la literatura de viajes de otras épocas y que las dotan de su carácter particular y único. ${ }^{1}$ Un elemento clave dentro de esta gramática

Enviado: 21-06-2016 / Aceptado: 26-07-2016

${ }^{1}$ Utilizo el término «relatos de viajes» de acuerdo con la propuesta de Luis Alburquerque, para, dentro de la categoría de literatura de viajes, hablar de textos factuales, testimonios de una experiencia vivida en oposición a los textos ficcionales centrados en el motivo del viaje. A estos, siguiendo a Alburquerque, me referiré como «novelas de viaje». Véase AlbuQuerque García, L., «"Relatos de viaje” y paradigmas 
interna, y que se erige a la vez como núcleo organizativo o dispositivo de los relatos, es la descripción. Llevar a cabo esa descripción no le había de resultar tan fácil al relator medieval como nos pudiera parecer a los lectores actuales. Como señala Rubio Tovar: «los viajeros medievales realizaron [...] un extraordinario esfuerzo para expresar con palabras el mundo que iban descubriendo». ${ }^{2}$ El papel del viajerorelator en la Edad Media era increíblemente complejo, ya que se encontraba en el conflicto entre lo que realmente veía y lo que se suponía que tenía que ver, entre la realidad contemplada y la imagen predeterminada de esta realidad. Rubio Tovar incide en este dilema:

Debemos, pues, reconocer en los viajeros el deseo, infrecuente en la literatura medieval, de describir lo que tenían delante, sin olvidar la carga de la tradición, que casi obligaba a éstos a ver lo que estaba escrito en los libros o era creencia popular. ${ }^{3}$

Los viajeros-relatores medievales se caracterizaban por su voluntad de describir lo visto con la máxima precisión y fidelidad, a pesar de la importancia de llevar tras de sí el peso de la tradición escrita: «los viajeros [...] fueron los únicos realistas frente a una cultura libresca». ${ }^{4}$ Por esta razón, el carácter documental e informativo de la obra de viaje es fundamental: «el libro de viajes adquiere valor por sí mismo en su intención informativa». ${ }^{5}$ Esto lleva al otro conflicto del viajero-relator: por un lado, siendo el detallismo «rasgo común a buena parte de la narrativa de gótico tardío y a los libros de viajes, en particular», ${ }^{6}$ en los textos de viajes destaca el interés por contarlo todo. No obstante, junto a este afán imposible por abarcarlo todo, resulta muy característico de los libros de viajes el intento constante de ir plasmando síntesis descriptivas. ${ }^{7}$ De esta forma, el relator medieval se ve obligado a conjugar -con el «extraordinario esfuerzo» del que habla Rubio Tovar- la precisión y el detallismo con la síntesis.

La descripción en los relatos medievales del viaje abarca muchos ámbitos y realidades. Quizá la desriptio urbis sea uno de los más característicos y estudiados, ${ }^{8}$ pero también la visión de la fauna exótica y maravillosa es uno de sus exponentes

culturales», en Letras, 71, 2015, pp. 63-76; y, del mismo autor, «El “relato de viajes": hitos y formas en la evolución del género», en Revista de Literatura, 73, 2011, pp. 15-34.

2 Rubio Tovar, J., Libros españoles de viajes medievales, Madrid, Taurus, 1986, p. 29.

3 Rubio Tovar, J., Libros españoles de viajes medievales, ob. cit., p. 27.

4 Rubio Tovar, J., Libros españoles de viajes medievales, ob. cit., p. 27.

5 López Estrada, F., Libros de viajeros hispánicos medievales, Madrid, Ediciones del Laberinto, 2003, p. 79.

6 Beltrán Llavador, R., «Los libros de viajes medievales castellanos», en Revista de Filología Románica, anejo 1, 1991, pp. 124.

7 López Estrada, F., Libros de viajeros, ob. cit., p. 114.

8 Pérez Priego, M. Á., «Estudio literario de los libros de viajes medievales», en Epos: Revista de filología, 1, 1984, pp. 217-240. 
más reconocibles. Partimos de la gran cantidad y concentración de procedimientos descriptivos utilizados para llevar a cabo el reflejo más fiel de la realidad desconocida:

Para describir esta realidad totalmente nueva y acercarla al público receptor, permitiéndole construir una imagen mental del animal, los relatores despliegan un verdadero concentrado de recursos discursivos que incluyen la comparación, la adjetivación, la referencia a las medidas, así como el uso de la hipérbole. ${ }^{9}$

El viajero tiene que hablar de una realidad nueva, describiendo lo nunca visto, por lo que busca puntos de referencia en lo conocido. En la descripción medieval del animal exótico, visto siempre como una verdadera maravilla, es decir algo admirabilis, insólito y digno de atención a ojos de los viajeros, «la realidad del animal se compara con lo que el relator (y también luego los oyentes y lectores) conocen por su habitual experiencia con los animales». ${ }^{10}$ De esta forma, la descripción detallada de animales nuevos -nunca vistos por el hombre europeo- que los viajeros medievales van descubriendo a lo largo de su recorrido, tratando de hacer partícipes a sus lectores de ese conocimiento, constituye uno de los rasgos más característicos de los textos de viajes de esta época.

Partiendo de esas premisas, el objetivo de este artículo será, en primer lugar, analizar algunas de las más llamativas de estas descripciones de animales en los relatos de viajes medievales, para a continuación poder compararlas con el tratamiento que reciben en algunas novelas históricas contemporáneas de viaje medieval. Así, se resumirán algunos de los aspectos más relevantes que han sido ya destacados a la hora de estudiar las descripciones de animales exóticos presentes en dos de las obras hispánicas fundamentales de literatura de viajes: Embajada a Tamorlán y Andanças y viajes de Pero Tafur, incorporando, siquiera brevemente, alguna otra foránea, como el Diario de viaje de Johannes Schiltberger. Partiendo del comentario de los procedimientos retóricos utilizados en estas obras, se analizará el tratamiento que se hace de los mismos animales exóticos en dos textos contemporáneos centrados en el viaje medieval: En busca del unicornio de Eslava Galán y Embajada a Samarcanda de Fernando Martínez Laínez.

Antes de pasar a la visión de los animales exóticos en el corpus seleccionado, resulta importante matizar que, aunque todos los títulos mencionados forman parte de la literatura de viajes, su carácter es muy distinto. Mientras que los textos medievales constituyen testimonios reales de periplos realizados y constatados históricamente, las novelas históricas pertenecen al mundo de la ficción. ${ }^{11}$ Por esta razón, tal y como indicaría Alburquerque, Embajada a Tamorlán y Andanças y viajes de Pero Tafur, así como

\footnotetext{
9 BéGuelin-Argimón, V., La geografía en los relatos de viajes castellanos del ocaso de la Edad Media. Análisis del discurso y léxico, Lausanne, Hispania-Helvética, 2011, p. 218.

10 López Estrada, F., Libros de viajeros, ob. cit., p. 84.

11 Véase supra (n. 1) la neta diferencia establecida por L. Alburquerque.
} 
el diario de Johannes Schiltberger, dado su carácter factual, podrían considerarse relatos de viajes, mientras que En busca del unicornio y Embajada a Samarcanda pertenecerían a las novelas de viajes. Sin embargo, la adscripción de estas obras a diferentes grupos de la literatura de viajes no impide analizarlas en el mismo estudio, pues ofrecen la oportunidad de poder comparar y reflexionar sobre la importancia y el significado de estas descripciones dentro de textos de distantes épocas y de características diferentes, pero siempre partiendo del viaje medieval.

\section{Los animales exóticos en la Embajada a Tamorlán, Andanças y Viajes de Pero TAFUR Y EL DIARIO DE VIAJE DE JOHANNES SCHILTbERGER}

La descripción de los animales exóticos resulta, como ya se ha comentado, una de las más significativas que pueden ofrecer los relatos de viajes medievales. El elemento más destacable en ella es la extensa prosopografía (en su variante zoográfica) que llevan a cabo los relatores-viajeros. Sin ánimo de querer cubrir con exhaustividad todo el repertorio de fauna exótica descrita, me limitaré a los casos más llamativos de las obras seleccionadas, donde la explicación de los rasgos físicos del nuevo animal descubierto ocupa un lugar muy importante. En Embajada a Tamorlán los embajadores comentan el aspecto de la jirafa de la siguiente forma:

La cual animalia era fecha d'esta guisa: avía el cuerpo tan grande como un cavallo, e el pescueço muy luengo; e los braços, mucho más altos que las piernas; e el pie avía así como el bue, e fendido; e desde la uña del braço fasta encima del espalda, avía fasta diez e seis palmos; e desde las agujas fasta la cabeça, avía fasta otros dies e seis palmos. [...] E el pescueço avía delgado, como ciervo, e las piernas avía muy cortas segund la longura de los braços. E omne que no la oviese visto, bien pensaría que estava asentada. E las ancas avía derrocadas ayuso como búfano; e la barriga blanca; e el cuerpo, de color dorado e rodado de unas ruedas blancas e grandes. E el rostro avía como de ciervo; e en lo baxo de faza las narices e en la fruente, avía un cerro alto, agudo; e los ojos, muy grandes y redondos; e las orejas, como de cavallo; e cerca d'las orejas tenía dos cornezuelos pequeños redondos, e lo más d'ellos, cubiertos de pelo, que parescían a los del ciervo cuando le nascen. ${ }^{12}$

La descripción que de este animal hace Pero Tafur, aunque menos extensa, también resulta bastante detallada:

Otro dia siguiente fuí a ver una animalia que llaman Xarafia, que es tan grande como un grant çiervo, é tiene los braços tan altos como dos braças é las piernas tan cortas como un cobdo, é toda la fazion como una cierva, é rodada, las ruedas blancas é amarillas, el cuello tan alto como una raçonable torre, é muy mansa. ${ }^{13}$

\footnotetext{
12 López Estrada, F. (ed.), Embajada a Tamorlán, Madrid, Castalia, 1999.

13 Jiménez de la Espada, Marcos (ed.), [Pero Tafur] Andanças e viajes de un hidalgo español, estudio y descripción de Roma por José Vives Gatell; presentación bibliográfica de Francisco López Estrada,
} 
Como se puede apreciar en estos fragmentos la comparación es el recurso primordialmente utilizado. Para presentar el animal nuevo se recurre constantemente a la comparación de sus rasgos con los de una fauna conocida. En Embajada a Tamorlán la descripción de la jirafa es la suma de una serie de elementos característicos de diferentes animales similares: su cuerpo parece ser el del caballo, su pie recuerda el del buey, su cuello es como el del ciervo, etc. Pero Tafur, en cambio, se centra en comparar sus dimensiones con las medidas de otros animales conocidos: «tan grande», «tan altos», «tan cortas»... En ambas descripciones aparecen diversos adjetivos a través de los cuales «[...] se refieren los relatores a la forma, el tamaño y el color del animal [y] a las distintas partes de su cuerpo...». ${ }^{14}$

También el viajero alemán Johannes Schiltberger, que acompañó a su señor Leonhard Reichartinger en la cruzada de Nicópolis, cayendo en 1396 en cautiverio turco, en su diario de viaje menciona la jirafa, pero la descripción que hace de este animal no resulta tan detallada: ${ }^{15}$

He estado también en la Pequeña India. Es un buen reino y su capital se llama Dily. En esta tierra hay muchos elefantes y también un animal que se llama Surnasa. ${ }^{16}$ Se parece al ciervo, pero es muy alto y tiene un cuello muy largo que mide unas cuatro brazas o más. Delante tiene largas patas y detrás cortas. En la Pequeña India hay mucho de este animal. ${ }^{17}$

Lo que llama la atención en esta descripción es la comparación de la jirafa con el ciervo, igual que ocurre en los otros dos relatos. Pero, a diferencia de los relatos hispánicos, en su diario Schiltberger se centra casi exclusivamente en el tamaño del animal, intentando aportar las medidas lo más exactas posibles: «es muy alto», «tiene un cuello muy largo que mide unas cuatro brazas o más», «delante tiene largas patas y detrás cortas». La descripción del viajero alemán es, por tanto, mucho más escueta y su objetivo no es plasmar la visión lo más completa posible del animal exótico, sino presentarlo de una manera objetiva, casi científica, centrándose en el tamaño, el único parámetro posible de plasmar de manera más o menos fiel y empírica.

Barcelona, El Albir, 1982.

14 Béguelin-Argimón, V., La geografía en los relatos de viajes, ob. cit., p. 218.

15 La traducción es mía, a partir del fragmento original del texto, en alemán moderno: «Ich bin auch in Kleinindien gewesen. Das ist ein gutes Königreich, und seine Hauptstadt heißt Dily. In diesem Land gibt es viele Elefanten und auch ein Tier, das Surnasa heißt. Es ist dem Hirsch ähnlich, jedoch sehr hoch und hat einen langen Hals, der etwa vier Klafter oder mehr mißt. Vorne hat es hohe Beine und hinten kurze.Von diesen Tieren gibt es viele in Kleinindien» (JohANnes Schiltberger, Als Sklave im Osmanischen Reich und bei den Tataren, U. Schlemmer (ed.), Stuttgart, Thienemann, pp. 130-132).

16 Surnasa es el nombre que designa este animal en la versión moderna del relato. En alemán medieval el autor se refiere al animal como Suruafa, mientras que die Giraffe es la denominación en alemán actual.

17 JohANnes Schiltberger, Als Sklave im Osmanischen Reich und bei den Tataren, ob. cit., pp. 130-132. 
El segundo animal descrito por los embajadores del rey Enrique III y por Pero Tafur es el elefante (o «marfil»). Los primeros dedican un espacio importante a la descripción física de este ser tan exótico:

E los dichos marfiles eran negros, e no han pelo ninguno, salvo en la cola que an como cavallo, que an unas pocas de sedas. E eran grandes de cuerpo, que podían ser cuatro o cinco toros grandes. E el cuerpo an mal fecho, sin talle, como un grand costal que estudiese lleno. E las ancas an derrocadas faza ayuso como búfano; e las piernas, muy gruesas e parejas; e el pie, redondo, todo carne, e tiene cinco dedos en cada uno, con sus uñas, como de hombre negras. E no han pescueço ninguno, salvo luego en las agujas, que las han muy grandes; que tiene la caveça pegada. [...] E las orejas, muy grandes e redondas, farpadas, e los ojos, pequeños. E la cabeça ha muy grande e fecha como de una alvarda de asno pequeña; e encima de la cabeça, á un foyo. [...] E debaxo d'esta trompa tiene la boca e las quixadas de baxo tiénelas como cochino o como puerco; e en estas quixadas de baxo tiene dos colmillos tan gruesos como la pierna de un omne e tan altos como una braçada. ${ }^{18}$

También Pero Tafur describe recurriendo a la comparación los elementos más destacados en la apariencia de este animal:

Este día volvimos á Babylonia, é otro dia siguiente fuemos á ver la casa donde están los elefantes, é fallé siete, los quales son negros de color é de grandeça más que camellos, é de fortaleça ansí de braços como de piernas que parescen mármoles, la mano redonda é con uña fuerte [...] tienen los ojos muy chequitos como un cornado é colorados, la cola corta como de osso, la oreja como una comunal adarga é la cabeza como de tinaja de estas seys arrobas, los colmillos de quatro palmos. ${ }^{19}$

Los relatores emplean, en sus bastante extensas descripciones de elefantes, los mismos recursos que en sus retratos de la jirafa. Bégelin-Argimón desgrana cómo en la Embajada el elefante, al igual que en el caso de la jirafa, es comparado con otros animales conocidos como el caballo, el cerdo o el oso, pero también con el hombre (sus uñas son como de hombre), e incluso con objetos (el cuerpo es como un costal lleno). Pero Tafur, a su vez, compara el elefante con el camello y el oso, y recurre también a la comparación con objetos. ${ }^{20}$

Además, ambos viajeros-relatores le prestan especial atención a la parte del cuerpo más característica de los elefantes, la trompa, dedicando varias líneas a la descripción de su aspecto y sus funciones. Pero mientras Pero Tafur se limita a comentar lo siguiente:

[...] tiene la boca muy chica, tiene el beço de arriba una trompa de fasta seys palmos esta él la aluenga quando él quiere, é la encoge quando quiere, é con esta apaña

\footnotetext{
18 Pero TAfur, Andanças e viajes de un hidalgo español, ob. cit., pp. 293-294.

19 Pero TAfur, Andanças e viajes de un hidalgo español, ob. cit., p. 87.

20 Béguelin-Argimón, V., La geografía en los relatos de viajes, ob. cit., p. 219.
} 
las cosas que a de comer é las mete en la boca, é fínchela de agua quando quiere beber. $^{21}$

Las observaciones de los embajadores resultan más minuciosas:

De la caveça se le sigue ayuso, do ha de tener la nariz, una como trompa, que es muy ancha arriba, y angosta ayuso, todavía más que se llega que se mengua fasta el suelo. E esta trompa es foradada, e por ella beve cuando ha gana e métela en agua e beve con ella e vale el agua a la boca así como si le fuese de las narizes. E otrosí con esta trompa pace, que no puede con la boca, que no se puede abaxar, e toma en esta trompa, cuando quiere comer, e rebuélvela a la yerva, e tira e siégala con ella como si fuese un focino. E desí apáñala con aquella trompa e faze un vuelco e revuélvela con aquella trompa, e métela en la boca, e desí cómela. E con esta trompa se mantiene e nunca la tiene queda, salvo faziendo vueltas con ella como culuebra. E esta trompa échala en el espinazo e no dexa lugar en todo su cuerpo onde no llega con ella. ${ }^{22}$

El interés de ambos relatos por esta parte del cuerpo no resulta tan sorprendente, ya que las funciones de la trompa han sido tratadas en diversos bestiarios medievales. ${ }^{23}$

La importancia de estos animales y de su descripción en los textos medievales no se debe exclusivamente al hecho de que formen parte del mundo desconocido que se intenta explicar y acercar al receptor, sino que se ha de analizar relacionado con el gran valor de muchos de los animales en el mundo medieval y a los múltiples papeles que estos desempeñaban. En síntesis de Béguelin-Argimón, se puede hablar del uso de los animales exóticos mencionados, como regalo o presente, como fuente de diversión y como pieza clave en la estrategia bélica. ${ }^{24}$ Estas tres funciones se ven reflejadas en las obras tratadas. Al igual que los embajadores llevan halcones del rey castellano como regalo para el Gran Tamorlán, la jirafa constituye un valioso presente para el Emperador enviado por el Sultán de Babilona. Asimismo, tanto los embajadores, como Pero Tafur, comentan los curiosos usos del elefante. Además, no solo en la Embajada sino también en el diario de viaje de Schiltberger se menciona el episodio en el que Tamorlán consiguió ganar a las tropas indias y a sus elefantes gracias a la estrategia de lanzar contra ellos camellos cargados de paja ardiendo. Igualmente, en Embajada se insiste en la posibilidad de domesticar el animal y aprovecharlo para determinados fines: «E es animalia muy entendida, e faze muy aína e presto lo que le manda el omne que lo guía»; «e tras las orejas va un omne cavallero que lo guía con un focino en la

\footnotetext{
21 Pero TAfur, Andanças e viajes de un hidalgo español, ob. cit., p.87.

22 López Estrada, F. (ed.), Embajada a Tamorlán, ob. cit., p. 294.

23 Véase Malaxecheverría, I., Bestiario medieval, Madrid, Siruela, 1986, y Sebastián, S. (ed.), El Fisiólogo atribuido a San Epifanio y El Bestiario toscano, Madrid, Tuero, 1986.

24 Béguelin-Argimón, V., La geografía en los relatos de viajes, ob. cit., p. 215.
} 
mano, e le faze andar a do quiere». ${ }^{25}$ Por esta razón se hace especial hincapié en la función bélica del elefante, insistiendo en sus ventajas como herramienta de guerra, así como en su utilidad en las operaciones miliares: «e tengo de verdat, segund lo que en ellos vi, que en una batalla deven de ser contados cada uno por mil omnes». ${ }^{26}$

El hecho de poder utilizar el elefante en la lucha aparece en el texto porque podría resultar interesante, llegado el momento, su aplicación en Europa. Como comenta López Estrada, «el redactor se refiere a la eficacia bélica de los animales como si escribiese una información para los estrategas de su Rey».27 Por esta razón, los embajadores no solo alaban la eficacia bélica del animal, sino que también explican los detalles necesarios para entender la estrategia de lucha con su uso: «E cuando les fazen pelear, en estos colmillos trahen unas argollas de fierro, e en ellas les ponen unas espadas, que son fechas como espadas de armas canalada, e no es más luenga que'l braço». ${ }^{28}$ También Pero Tafur menciona este uso del animal, pero mantiene una prudente reserva o distancia de la información que proporciona a través de la fórmula «dizen»: «Dizen que en la India que arman castillos sobre ellos en que van diez é seys onbres, é afórranles aquellos colmillos, quando quieren combatir, en açero».29

Asimismo, ambos textos destacan otra función del elefante: su participación en los diversos espectáculos como elemento de diversión. En la Embajada se comenta: «E con estos marfiles [elefantes] fazían este día muchos juegos, faziéndolos correr tras cavallos e tras la gente, que era grand plazer», ${ }^{30}$ mientras que Pero Tafur afirma lo siguiente: «Estas bestias paresçe como que tengan entendimiento; tantas burlas fazen, que á las vezes traen aquella trompa llena de agua, é échala encima á quien quiere é fázenlos jugar con una lança echándola en alto é rescibiéndola, é otros muchos juegos». ${ }^{31}$

El espacio dedicado al elefante en los textos tratados no sorprende, ya que se trata del animal que probablemente más interés despertó y más impresión causó al hombre medieval. ${ }^{32}$ La fascinación por este ser exótico se evidencia en el extenso espacio que se le dedica en el Fisiólogo y en los bestiarios medievales. La información complementaria que suele aparecer en los tratados didácticos medievales se relaciona, por otro lado, con la castidad de este animal y su falta de deseo carnal. Así, se difundió

25 López Estrada, F. (ed.), Embajada a Tamorlán, ob. cit., p. 293-294.

26 López Estrada, F. (ed.), Embajada a Tamorlán, ob. cit., pp. 295.

27 López Estrada, F. (ed.), Embajada a Tamorlán, ob. cit., pp. 293.

28 López Estrada, F. (ed.), Embajada a Tamorlán, ob. cit., pp. 294.

29 [Pero Tafur] Andanças e viajes de un hidalgo español, ob. cit., p. 88.

30 López Estrada, F. (ed.), Embajada a Tamorlán, ob. cit., p. 294.

31 [Pero Tafur], Andanças e viajes de un hidalgo español, ob. cit., pp. 87-88.

32 Sebastián, S. (ed.), El Fisiólogo atribuido a San Epifanio y El Bestiario toscano, ob. cit., p. 24. 
la idea de que antes de realizar el coito, la hembra elefante para despertar el deseo del macho busca una hierba (a veces, una mandrágora), que come, convenciendo a continuación al macho de que también la consuma. Lo que recuerda inequívocamente la historia bíblica, de manera que «el afrodisíaco que estimuló a los elefantes hacia el coito [funciona] como la manzana [que] llevó a Adán y Eva hacia la lujuria».33

Otras creencias en torno al elefante se refieren a su relación con los demás animales. Según los tratados medievales, es una bestia grande a la que temen otros animales, pero el mismo se asusta ante un ratón. Su mayor enemigo es el dragón, pero son famosos también los enfrentamientos de los elefantes con los rinocerontes, así como sus luchas con el unicornio. Asimismo, una nota constantemente presente en las páginas de los bestiarios alude a su falta de articulaciones rotulares, por lo que la forma más apropiada de cazarlo es buscar un árbol en el que se apoye para dormir y cortar parcialmente el tronco para que, al caer el árbol, caiga a la vez también el elefante. ${ }^{34}$ Esta estrategia aparece reflejada, entre otros, en el Libro de Alexandre, en la primera mitad del siglo xIII, lo que no sorprende, puesto que desde la Antigüedad el elefante aparecía vinculado al personaje de Alejandro Magno. La Embajada a Tamorlán y las Andanças y viajes de Pero Tafur repetirán, en fin, algunas de las ideas leídas o recordadas de los bestiarios, y Pero Tafur, en concreto, cuando comenta que «dizen que biven mucho estas animalias», ${ }^{35}$ recuerda los diversos breviarios medievales en los que se insistía mucho en la longevidad de estos animales.

Ambos relatos se centran, pues, en la descripción de algunos de los elementos más llamativos y sorprendentes, como la trompa del animal, así como su gran poder en la lucha, coincidiendo con las descripciones de los bestiarios. Lo que los relatores dejan de lado son las notas pertenecientes al mundo de las creencias fantásticas y el conocimiento libresco, como las menciones a la espiritualidad del animal y el paralelismo con los textos bíblicos. La ausencia de este tipo de comentarios puede deberse al afán de los viajeros por contar solo lo visto, lo empírico, sin incluir de manera acumulativa -sin la criba de la observación real- la tradición libresca. De esta forma, los detalles referentes a los animales exóticos en los que se fijan los relatores medievales, por un lado tienen un carácter práctico y utilitarista (como cuando insisten en el potencial de los elefantes para las guerras), pero por otro lado sirven para entender mejor la cultura de los nuevos pueblos conocidos y sus costumbres (y, ahí, el papel del animal como fuente de diversión).

\footnotetext{
33 Sebastián, S. (ed.), El Fisiólogo atribuido a San Epifanio y El Bestiario toscano, ob. cit., p. 29.

34 Curiosamente, en el llamado Codex Granatensis la manera de cazar el elefante no es talar el árbol en el que se apoya, sino vencerlo gracias a dos vírgenes: dos doncellas desnudas buscan al elefante, una llevando la espada y la otra una urna. El animal reconoce la inocencia de las muchachas y admira su castidad lamiendo sus senos. Cuando cae en un sopor una muchacha le clava la espada y la otra recoge la sangre en su urna (MALAXECHEVERRÍA, I., Bestiario medieval, ob. cit., pp. 47-48).

35 [Pero Tafur], Andanças e viajes de un hidalgo español, ob. cit., p. 88.
} 
Sin lugar a dudas, la jirafa y el elefante son los animales más característicos de los textos de viajes medievales. No obstante, también resulta interesante mencionar otros animales vistos por Pero Tafur durante su viaje. La siguiente bestia exótica que menciona el hidalgo andaluz es el cocodrilo. En su descripción física el animal es comparado con un lagarto: «Ésta es en todo fechura de lagarto; tienen los dientes macho é fembra arriba é abaxo, é por esto dizen que, quando travan alguna cosa, non pueden soltar tan ayna». ${ }^{36}$ Se insiste en lo peligroso que puede llegar a ser «...quando están en el agua, non ay ome ni bestia que puedan alcançar que non la matan»;37así como en sus costumbres y hábitos: «Estas bestias suelen salir fuera del agua çinco ó seys pasos, é quando faze sol están mucho adormeçidas». ${ }^{38}$ Finalmente, se detiene en describir con mucho detalle la forma de cazarlo.

Cuando Tafur habla del segundo animal acuático destacado, que ha de ser el hipopótamo, se distancia de la realidad descrita e insiste en que él mismo no lo ha visto: «dizen muchos -yo non lo vi- que en esta mesma rivera se crian otras bestias, que son cavallos ni más ni ménos, salvo que lo de la boca tienen tan ancho como lo de la frente, é salen pegados con el agua á pacer». ${ }^{39}$ Este interés en destacar no haber sido testigo presencial evidencia el esfuerzo de Tafur por transmitir los datos verídicos sobre la realidad nueva, sin rechazar, al mismo tiempo, la fiabilidad de los saberes de la gente que va encontrando en su camino. A la descripción del animal, que es comparado -etimológicamente- con el caballo y donde se destaca su gran boca, le acompaña también la mención a la manera de poder cazarlo y a su naturaleza «...e éstos nin en el agua nin fuera della non fazen mal». ${ }^{40}$ Estos comentarios indican que el objetivo del relator es plasmar en su texto la visión más completa de los animales desconocidos, sin concesiones a lo legendario, pero sin dejar de mencionar ningún detalle que pueda resultar útil para los receptores.

\section{LA NOVELA HISTÓRICA CONTEMPORÁNEA DE VIAJE MEDIEVAL Y LA DESCRIPCIÓN DE LOS ANIMALES EXÓTICOS}

La descripción de estos animales que ofrecen las novelas históricas contemporáneas centradas en el tema del viaje medieval resulta especialmente interesante como apertura para realizar una comparación retórica, de análisis narrativo y de funciones culturales. A diferencia de los relatos de viajes, donde en la mayoría

\footnotetext{
36 [Pero Tafur], Andanças e viajes de un hidalgo español, ob. cit., p. 75.

${ }^{37}$ [Pero Tafur], Andanças e viajes de un hidalgo español, ob. cit., p. 74.

38 [Pero Tafur], Andanças e viajes de un hidalgo español, ob. cit., p. 74.

${ }^{39}$ [Pero Tafur], Andanças e viajes de un hidalgo español, ob. cit., p. 75.

40 [Pero Tafur], Andanças e viajes de un hidalgo español, ob. cit., p. 75.
} 
de los casos quien realiza el trayecto es también el narrador de su propia experiencia (inscribiendo, de esta forma, su relato en la época en la que este se realizó), en la novela histórica de viaje medieval existe un desenfoque o desequilibrio de partida entre lo que es el viaje y lo que constituye su narración. Se trata de un viaje medieval, pero, inevitablemente, condicionado por una óptica contemporánea. ${ }^{41}$ La perspectiva del viaje del escritor está distorsionada por pertenecer este a una época distinta. De esta forma, se produce un efecto de extrañamiento, al hablarse de un viaje que no se puede experimentar, viaje realizado por otros, en otra época y con una cosmovisión diferente. Por esta razón, al escritor contemporáneo le resulta necesario conciliar el reflejo fiel de lo que pudo ser y significar un viaje en la Edad Media con la creación de una narración interesante, una obra atractiva que llegue a un público amplio, gracias a recursos propios de la narrativa moderna.

De la amplia gama de novelas históricas de tema medieval, me centraré en textos cuyo núcleo lo constituya el viaje medieval y en los que se pueda observar la importancia de la descripción en general y de las descripciones de animales exóticos en particular. Por esta razón las obras seleccionadas han sido la Embajada a Samarcanda (2003) de Fernando Martínez Laínez y En busca del unicornio (1987) de Juan Eslava Galán. La obra de Martínez Laínez guarda una relación directa con Embajada a Tamorlán, presentando una versión alternativa del famoso manuscrito medieval: Laura, una profesora de Historia Medieval, durante su viaje a Estambul, compra un antiguo manuscrito escrito en castellano. Resulta que son los hasta entonces perdidos apuntes personales de Ruy González de Clavijo. Como se explica en la novela, se trata de un relato que había redactado Clavijo de su viaje a Samarcanda, pero cuya difusión quedó prohibida por el rey.

La segunda obra seleccionada, En busca del unicornio, se centra en la expedición dirigida por Juan de Olid, criado del Condestable de Castilla, en busca del cuerno de unicornio por todo el continente africano (conocido y desconocido). La novela de Eslava Galán es un texto muy significativo en el panorama de la novela histórica, que marca todo el género. Su publicación, antes del boom de la novela histórica, fue todo un éxito -respaldado comercialmente por la obtención del premio Planeta en 1987- y significó, además, todo un cambio de orientación y apertura en el camino de la novela española de tema histórico. Por tanto, mientras que el acercamiento al primer texto, la novela de Martínez Laínez, resulta necesario por el contenido de su argumento y por su explícita vinculación directa con el original medieval de la Embajada a Tamorlán,

\footnotetext{
41 Esta cuestión está indisolublemente unida a la ya mencionada distinción entre el relato de viaje y la novela de viaje. En el relato de viaje el que realiza el viaje suele ser al mismo tiempo el relator de esta experiencia, mientras que en la novela de viaje el autor habla de un suceso ficticio, por lo que desaparece o se anula, obviamente, la identificación viajero-relator.
} 
el análisis del tratamiento de la descripción de animales en el segundo texto será igualmente inevitable y especialmente interesante, ya que se trata de una obra muy destacada -una de las más relevantes de las últimas décadas- dentro del panorama de la novela histórica, y en concreto de la de temática viajera y medieval.

El profundo conocimiento del texto medieval de Embajada que atesora el autor de su versión moderna, es incuestionable. No cabe ninguna duda de que Martínez Laínez a la hora de elaborar esta, se propuso seguir muy de cerca el original medieval. El eco de Embajada a Tamorlán está omnipresente y lo pueden atestiguar diferentes historias presentes en el original medieval, que se repiten en el relato contemporáneo. Tanto en el texto medieval como en la versión de Martínez Laínez se comenta, por ejemplo, la general sorpresa ante la abstinencia de Clavijo o se habla de la gran fiesta en la que los artesanos y comerciantes reciben permiso para vender dentro del ordo. Igualmente, ambos textos cuentan la historia de Tamorlán y su llegada al poder, e insisten en la superioridad de los embajadores castellanos ante los mensajeros de Catay. De la misma forma, el autor conoce perfectamente la descripción de los animales exóticos presentes en el original y, como se verá a continuación, la sigue fielmente.

Así, la descripción de la jirafa parece ser la versión modernizada, sin cambios sustanciales, de la descripción presente en el texto medieval. Tanto la introducción del tema como su desarrollo en el original medieval y en la versión contemporánea son idénticos:

El embajador llevaba también seis avestruces, además de la jornusa o jirafa, el cual animal tenía el cuerpo tan grande como un caballo, el pescuezo muy luengo, los brazos más altos que las piernas, y el pie hendido como de buey. Desde la pezuña hasta la cima de la espalda podían medirse dieciséis palmos. Y el pescuezo enhiesto tenía delgado como el de un ciervo, con las piernas cortas en proporción a los brazos, de manera que quien no le hubiese visto bien pensaría que estaba sentado. La barriga tenía blanca y el cuerpo de color dorado, rodeado de unas manchas blancas y grandes. Y la cabeza como de venado, con los ojos muy grandes y redondos, y las orejas como de caballo. Cerca de las orejas tenía dos cuernecillos redondeados en la punta y cubiertos de pelo, que parecían a los del ciervo cuando le nacen. ${ }^{42}$

La descripción de Martínez Laínez es un fiel espejo del original medieval, sustituyendo el castellano medieval por su versión moderna. En lo demás la descripción de la jirafa de Martínez Laínez sigue línea por línea la descripción presente en el relato antiguo. El animal otra vez se describe a base de comparaciones, según las cuales su cuerpo se parece al del caballo, su pie es como el del buey, el pescuezo como el del ciervo, etc. La forma de explicar las medidas es la misma que en el original: «el pescuezo muy luengo, los brazos más altos que las piernas», «las piernas cortas en

42 Martínez Laínez, F., Embajada a Samarcanda, Barcelona, Belacqua, 2003, p. 167. 
proporción a los brazos», etc. Los hábitos alimenticios del animal también son copia del fragmento original: «Comía hojas, y tan largo tenía el pescuezo que bien podría alcanzar a comer encima de unas paredes de cinco o seis tapias en alto, o también en la copa de un árbol». Y al igual que en el relato medieval, también en la novela aparece la idea de lo maravilloso, ya que el comportamiento del animal resulta asombroso para quienes lo ven por primera vez: «[...] de forma que a quien, como nosotros, nunca lo hubiese visto, le parecía cosa maravillosa de ver».43

En el caso del elefante, la descripción sigue el mismo criterio que en el de la jirafa. Estamos ante una copia, en castellano modernizado, de lo ya descrito en Embajada a Tamorlán:

Los dichos elefantes eran negros, enormes de cuerpo, como cuatro o cinco toros grandes, sin pelo alguno salvo en la cola, que tienen como de caballo. Su figura es como un costal lleno, sin talle, con las piernas muy gruesas y juntas y el pie redondo, todo carne con cinco dedos en cada uno y las uñas negras. Tienen la cabeza grande, sin cuello y pegada al cuerpo. De la cabeza se le sigue, do había de estar la nariz, como una trompa ancha arriba y angosta debajo que le llega hasta el suelo y nunca está quieta sino dando siempre vueltas, como si fuera culebra. ${ }^{44}$

Además, de la misma forma que en el texto original, se le da mucha importancia a la trompa, describiéndola al detalle:

La trompa es horadada, y con ella bebe agua que se lleva a la boca, y también la usa para pacer cuando quiere comer, pues con ella puede arrancar la hierba y segarla como si fuera una hoz. Pasé a exponer a la embobada corte otras cosas del elefante, y así les dije que este animal tiene debajo de las quijadas dos colmillos de marfil tan gruesos como la pierna de un hombre, y tan largos como un brazo. ${ }^{45}$

En el texto de Martínez Laínez se insiste en la eficacia bélica de estos animales, recurriendo a las mismas ideas y formulaciones que aparecen en el original. Se comenta que es un animal muy fuerte y decisivo en la batalla, que se puede guiar con un focino, es decir, con una vara larga de punta curva. Otro ejemplo en el que se evidencia la inclusión de las ideas del original en la novela es el fragmento referente a las heridas del animal, recogiendo la superstición medieval. Donde el texto antiguo reza: «E la ferida que le dan, luego esa noche la sana, si lo dexan al sereno; que si lo dexan so tejado, morría», ${ }^{46}$ el texto actualizado dirá: «Es cosa curiosa que la herida sana por la noche si al animal lo dejan al sereno, pero si lo dejan bajo techo muere». ${ }^{47}$ Frente a esta fidelidad

43 Martínez Laínez, F., Embajada a Samarcanda, ob. cit., p. 168.

${ }^{44}$ Martínez Laínez, F., Embajada a Samarcanda, ob. cit., p. 145.

45 Martínez Laínez, F., Embajada a Samarcanda, ob. cit., p. 145.

46 López Estrada, F. (ed.), Embajada a Tamorlán, ob. cit., p. 294.

47 Martínez Laínez, F., Embajada a Samarcanda, ob. cit., p. 145. 
o reverencia prácticamente absoluta al relato medieval, pueden sorprender pequeñas diferencias en datos cuantitativos respecto al aguante del elefante. Mientras en el texto original se comenta que «[...] dezían que tres días podían pelear sin comer», ${ }^{8}$ la novela matiza: «[...] pueden aguantar peleando sin comer ni beber hasta dos días». ${ }^{49}$ Resulta difícil constatar si esta diferencia se debe al descuido del autor contemporáneo o tiene alguna explicación, más allá de la simple atenuación.

Como se ha visto, a la hora de describir los animales exóticos, la novela se limita a actualizar el texto medieval, desde la copia prácticamente literal. ¿Por qué Martínez Laínez ha optado por esta solución? ¿Es un efecto de falta de creatividad del autor, de la imposibilidad de presentar otra alternativa a la descripción medieval? No lo parece. El autor, a lo largo de su novela, no siempre se muestra tan fiel al original. En la versión contemporánea aparecen múltiples desarrollos argumentales inexistentes en el texto medieval, del mismo modo que no siempre se tratan todos los temas del original. No obstante, en lo referente a las descripciones de los animales exóticos, como acabamos de comprobar, se sigue el manuscrito medieval al pie de la letra. Este procedimiento puede ser el resultado de la decisión consciente de plasmar en su texto el estilo y la mentalidad de la época, preocupación que, como él mismo comenta, le ha acompañado a lo largo de todo el proceso creativo.

El caso de En busca del unicornio de Juan Eslava Galán resulta mucho más interesante para el análisis, ya que, al no tener ningún referente real en la literatura medieval y actuar directamente en el campo de la ficción literaria, el texto ofrece más posibilidades en el tratamiento del tema de los animales. Eslava Galán imita y utiliza los moldes descriptivos medievales, pero sin llegar a copiarlos literalmente. Además, junto a las descripciones de animales exóticos de prácticamente obligada presencia, como el elefante y la jirafa, también ofrece la descripción de uno de los animales medievales fabulosos por excelencia: el unicornio.

Lo primero que llama la atención de la descripción de la jirafa en la novela de Eslava Galán es la ubicación del animal dentro de lo maravilloso: «Y a los dos o tres días de caminar por esta plana, entre los grandes yerbazales, hacia el Mediodía, topamos con el animal más maravilloso que imaginarse pueda y algo asombroso de ver». ${ }^{50}$ De la misma forma que para los otros viajeros, también para el narrador, Juan de Olid, la jirafa es un ser nuevo y muy curioso, lo que le conduce a describirla:

$\mathrm{Y}$ este animal tiene en todo la forma y hechura de un venado y cuatro patas y el color pardo y la cabeza chica y apuntada. Mas las patas las tiene luengas como tres

\footnotetext{
48 López Estrada, F. (ed.), Embajada a Tamorlán, ob. cit., p. 296.

49 Martínez Laínez, F., Embajada a Samarcanda, ob. cit., p. 146.

50 Eslava Galán, J., En busca del unicornio, Barcelona, Planeta, 1991, pp. 169.
} 
veces las del venado y el pescuezo lo tiene luego como dos hombres puestos uno encima del otro. Y con este pescuezo alcanza a comer los brotes tiernos y frutos de arriba de los árboles. [...] Y la cuerna la tiene más chica, que sólo traen dos cuernos, cortos más que las orejas, y muy romos de punta así como los del caracol. [...] Y con estos cuernos no atacan ni se defienden. ${ }^{51}$

Curiosamente, el autor, más que comparar cada parte del cuerpo de la jirafa con las de otros animales conocidos, se centra, en primer lugar, en su captación general y, en segundo lugar, en sus medidas. El animal, dice, se parece mucho a un venado (lo que recuerda las comparaciones con el ciervo de los textos anteriores). Pero, además, compara sus medidas con las de otros animales: «Mas las patas las tiene luengas como tres veces las del venado»; e incluso con las medidas humanas, recurriendo en este caso a la hipérbole: «el pescuezo lo tiene luego como dos hombres puestos uno encima del otro». También llama la atención la acumulación en polisíndeton de sintagmas, tratando de emular el procedimiento sintáctico habitual en las descripciones de los textos medievales. Sorprendentemente, la única comparación de una de las partes del cuerpo de la jirafa con las del otro animal es la que graciosamente -y agudamentecontrasta sus cuernos con los de un caracol. Además, se aprovecha la mención a los cuernos para aclarar que su función no es la que podría parecer, es decir: atacar o defenderse. Igualmente, aparecen diversos adjetivos que se refieren tanto al tamaño de las partes del cuerpo de la jirafa (la cabeza «chica» $\mathrm{y}$ «apuntada», los cuernos «cortos» $\mathrm{y}$ «romos»), como a su color.

Se puede observar que Eslava Galán crea su propio discurso a la hora de realizar la descripción del animal exótico, emulando, pero no copiando las formas o estructuras clásicas de las descripciones medievales. El autor no se limita a reproducir la información presente en los textos medievales, sino que también añade datos nuevos, como los referidos a la naturaleza del animal:

Y es animal muy espantadizo y de poco corazón, que en sintiendo ruido luego da en correr con aquellas sus luengas patas y el pescuezo lo va echando para adelante y para atrás como si repartiera su gran peso por no abocinarse y perder carrera. $Y$ estos ciervos del pescuezo largo no se están nunca solos, sino que van en manadas de quince o veinte y en esto también se parecen a los nuestros. ${ }^{52}$

Se pretende imitar el estilo del castellano medieval, lo que se evidencia, entre otros, en el polisíndeton de la conjunción copulativa «y» (al principio de la oración y frecuentemente repetida). También se remeda el esfuerzo medieval por aclarar la realidad nueva, al dar explicación, por ejemplo, a la forma peculiar de correr que tiene el animal: «con aquellas sus luengas patas y el pescuezo lo va echando para adelante

51 Eslava Galán, J., En busca del unicornio, ob. cit., pp. 169-170.

52 Eslava Galán, J., En busca del unicornio, ob. cit., p. 169. 
y para atrás como si repartiera su gran peso por no abocinarse y perder carrera». En este mismo fragmento se refleja la imposibilidad de denominar a este animal exótico (a diferencia de otros textos, aquí el viajero no sabe que se trata de una «jornusa» o jirafa), por lo que recurre a una perífrasis, convirtiendo la jirafa en un «ciervo del pescuezo largo». Finalmente, a diferencia de los relatos tratados, en la novela de Eslava Galán se mencionan reflexiones personales del protagonista, vinculadas a la experiencia del viaje y, aquí en concreto, al consumo de carne del animal en cuestión:

Y la mejor carne y más fina y más sabrosamente especiada que comimos desde que entramos en el país de los negros fue la de estos ciervos cuando cazamos uno y lo ballesteamos y con sólo el pescuezo comimos los treinta hombres que aún quedábamos, entre blancos y negros. ${ }^{53}$

Puede resultar hiperbólica la afirmación «con sólo el pescuezo comimos los treinta hombres», pero sirve para resaltar una vez más la asombrosa longitud del cuello de este animal.

La descripción del segundo animal exótico resulta igual de retóricamente elaborada que la de la jirafa. El viajero inmediatamente asocia a los elefantes con una realidad asombrosa e increíble: «y los dichos elefantes son grandes a maravilla porque cada una de estas bestias será alta como dos hombres o más». ${ }^{54}$ La base de esta primera presentación es su medida, en este caso también algo -pero no demasiado- hiperbolizada, equivalente a la de dos hombres. A esta primera observación le siguen diferentes comentarios, donde se mezcla la descripción física del animal con la explicación de las funciones de las diversas partes de su cuerpo, así como su comportamiento:

Y el cuerpo lo tienen grueso más que pensarse pueda, que más parece panza de nao que de animal vivo. Y el dicho cuerpo lo sostienen por cuatro patas muy gordas y fuertes que son como troncos de árboles recios y huesudas y llenas de matalones. Y la cabeza es como una barrica de cien arrobas y los ojos chicos, no más grandes que los de vaca, pero las orejas son llanas y grandes como estandarte de concejo y con ellas se abanican muy gentilmente en las horas de calor, que por la mucha grosura de sus cuerpos los aqueja mucho y las suelen pasar metidos en el agua de los ríos o echados sesteando en la hierba fresca, a la sombra de los árboles. Y la nariz la tienen larga a maravilla, como brazada de hombre o más, y la mueven con gran presteza como si brazo fuera y con un como dedo que en la punta trae van arrancando la yerba y los frutos de que comen y luego, retrayéndola, la llevan a la boca que es pequeña y escondida pero con grandes dientes. Y de la dicha boca le salen a cada lado dos como cuernos blancos y muy poderosos que están hechos de marfil y de ellos sacan sus cuentas y baratijas los negros y aun mangos de puñales y otras figuras de aprecio. ${ }^{55}$

\footnotetext{
53 Eslava Galán, J., En busca del unicornio, ob. cit., p. 170.

54 Eslava Galán, J., En busca del unicornio, ob. cit., p. 173.

55 Eslava Galán, J., En busca del unicornio, ob. cit., p. 174.
} 
Lo primero que se aborda en la descripción del elefante es la evidencia del escaso o nulo parecido de su cuerpo con el de otros animales, lo que lo convierte en un ser todavía más exótico. Para hablar del elefante, al igual que en los relatos medievales comentados, se recurre a contrastar sus partes del cuerpo con las de otros animales conocidos. No obstante, en la novela de Eslava Galán se observan comparaciones curiosas e inexistentes en los textos antes tratados: las patas del animal son como «troncos de árboles recios», mientras que sus orejas son tan planas y grandes como un «estandarte de concejo». Se observa la dificultad de denominar de forma unívoca la realidad nueva de este animal. Por esta razón, en el caso de los colmillos, se utiliza la fórmula «como», para dar a entender que parecen ser una especie de cuernos, pero no cuernos exactamente: «le salen a cada lado dos como cuernos blancos». Asimismo, se aprovecha la mención de los colmillos para comentar sus diversos usos entre los negros. También en esta descripción se recurre a la perífrasis, llamando a la trompa «nariz larga a maravilla». Se explica su uso y se comenta su medida que equivale a «brazada de hombre». Igualmente, se menciona graciosamente -con una irónica personificación- una de las funciones de las orejas, con las cuales «se abanican muy gentilmente en las horas de calor». Se aprovecha esta mención al calor que molesta al animal para explicar otra de sus costumbres, que consiste en pasar muchas horas «metidos en el agua de los ríos o echados sesteando en la hierba fresca, a la sombra de los árboles». La prosopografía del elefante se ve completada con múltiples adjetivos, cuyo objetivo es principalmente subrayar la grandeza del animal: patas «gordas y fuertes», orejas «llanas y grandes», cuernos «blancos y muy poderosos».

$Y$, de manera similar al caso de la jirafa, se comenta el carácter del animal: «Y el elefante es manso, debido a su mucha grosura, más si se asusta u ofende luego se torna terrible y con sus patas y los dichos dientes largos puede un elefante solo matar a muchos hombres». ${ }^{56}$ Se señala su naturaleza apacible, pero al mismo tiempo su peligrosidad y la posible amenaza que puede constituir, lo que recuerda los pasajes examinados anteriormente referentes a la eficacia bélica de esta bestia. También en el caso de la descripción del elefante se pretende ofrecer una visión completa del animal, totalmente inspirada en la retórica de la descriptio medieval, pero sin llegar a caer, como en la Embajada a Samarcanda, en la copia literal de la misma.

No obstante, no serán ni la descripción de la jirafa ni la del elefante las más originales de esta novela en lo que se refiere a inventio retórica. Lo que diferencia En busca del unicornio de los textos anteriormente comentados es la introducción y descripción de la figura del unicornio, sin contar la construcción de toda una trama argumental, sintetizada en el título de la novela, en torno a este animal fabuloso. El

56 Eslava Galán, J., En busca del unicornio, ob. cit., p. 174. 
autor convierte este animal propio y tan significativo dentro del universo medieval en el objeto de la expedición que hace el protagonista de su novela. Previamente, en la Embajada a Tamorlán, el relator, en su búsqueda de información objetiva, ni siquiera menciona la posibilidad de existencia de este animal fabuloso, y en la Embajada a Samarcanda, como fiel seguidora del texto del siglo $\mathrm{xv}$, tampoco se hace alusión alguna. En el caso de Pero Tafur, el lector se entera de la existencia del unicornio solo por el relato que Nicoló di Conti le hace al propio Tafur de algunas de las maravillas orientales asociadas al reino del Preste Juan. Curiosamente, en la obra de Schiltberger, en una especie de cuento popular que aparece en el relato, se hace mención a este animal, aunque no se describe. ${ }^{57}$ Sorprendentemente, en el texto del viajero alemán el unicornio es un animal cruel y malvado, lo que corresponde a la visión que se tenía de él en algunos bestiarios de la época, como el bestiario toscano y el Libellus de natura animalium..$^{58}$ No obstante, se trata de una visión minoritaria, ya que, por lo general, de acuerdo con los bestiarios medievales, el unicornio era el único ser que podía quitar el veneno del agua contaminada por la serpiente y representaba la figura del Salvador.

En su tratamiento de este animal, Eslava Galán recurre claramente a tratados medievales, pero más que hablar de su naturaleza, describiéndola por partes, como en los casos de la jirafa y el elefante, insiste en las propiedades mágicas de su cuerno, ya que estas hacen de él el objetivo de la expedición. Como se comenta en las primeras páginas de la novela: «El cuerno del unicornio es el remedio universal contra el veneno; el ungüento de su hígado es mano de santo en las heridas»; ${ }^{59}$ pero, sobre todo: «[...] apuntala la virilidad desfalleciente de los hombres poderosos en el otoño de sus vidas y les devuelve los ardores de la juventud $\gg{ }^{60}$ No obstante, antes de emprender el viaje, al protagonista se le advierte también de lo peligroso que es el animal en cuya búsqueda va a partir, con la finalidad secreta de intentar salvar o paliar la supuesta impotencia del rey Enrique IV:

[...] es muy feroz y nada puede resistir a su cornada, ni broquel ni adarga doblada

[...]. Su mayor enemigo es el elefante, al que vence y mata atravesándolo con su

\footnotetext{
57 Parece que se trata de una leyenda o cuento del folclore popular. Según el relato, en las montañas cercanas a Roma había un lindworm (especie de dragón) y un unicornio que causaban grandes daños a la gente. Nadie pudo encontrar remedio contra ellos. Por eso el papa Silvestre pidió al rey de Armenia que en nombre de Dios matara a las bestias. El rey partió totalmente solo a buscar el escondrijo de los animales y vino justo cuando estos estaban peleando. Aprovechó esta situación para cortarle la cabeza al lindworm y después mató al unicornio, liberando de esta forma a los habitantes de Roma de estos monstruos. Schiltberger, J., Als Sklave im Osmanischen Reich und bei den Tataren, ob. cit., pp. 218-219.

58 Véase MalatXeVerRía I., Bestiario medieval, ob. cit.

59 Eslava Galán, J., En busca del unicornio, ob. cit., p. 21.

60 Eslava Galán, J., En busca del unicornio, ob. cit., p. 20.
} 
cuerno. Un cuerno largo y retorcido que aguza contra las piedras como el cochino de monte afila sus colmillos. ${ }^{61}$

En este fragmento se refleja el pensamiento común de los tratados medievales, según el cual el gran enemigo del unicornio es el elefante. No obstante, la idea centrípeta, recurrente a lo largo de toda la novela, se refiere a la única forma de cazar el animal, es decir, con la ayuda de una virgen: «[...] pero nosotros lo cazaremos con una virgen».62 La versión de la caza del unicornio explicada en la obra es la que se cuenta que propone el naturalista latino: «Plinio certifica que el unicornio huele a la doncella y va a posar su cabeza terrible en el regazo de la niña: entonces se deja cautivar fácilmente porque abandona su habitual fiereza y la torna en mansedumbre».63

Aunque al principio de la novela no se muestra mucha atención al aspecto del animal, a lo largo de la expedición empiezan a aparecer los comentarios referentes a su apariencia física. La descripción que hacen del unicornio las tribus africanas que la expedición encuentra por el camino destaca los dos aspectos más importantes de este animal misterioso: su cuerno y las propiedades de este: «vieran animales como aquel que decíamos y que pacían yerba y eran grandes y tenían un cuerno encima del hocico y que los polvos de raspadura de este cuerno eran apreciada medicina en el trato venéreo». ${ }^{64}$

No obstante, la descripción más importante se ofrece en el momento en que el protagonista cree haber encontrado el animal que era el objetivo de su expedición:

Y ya en esta distancia se podía distinguir bien el único cuerno del unicornio que no era como yo me lo había esperado ni como fray Jordi, que atrás quedaba, me lo había descrito, esto es, muy largo y blanco y retorcido y afilado, sino más bien corto y recio, de la forma del miembro del hombre, un poco curvo hacia arriba. $Y$ no lo llevaba el unicornio en la frente sino en medio del hocico, como dijeran los tongaya. ${ }^{65}$

El fragmento que refleja la mirada de Juan de Olid cuando cree haber topado con el unicornio resulta muy interesante. Lo que llama la atención es el hecho de que, en realidad, el lector está ante dos descripciones distintas, de la misma forma que el

61 Eslava Galán, J., En busca del unicornio, ob. cit., p. 20.

62 Eslava Galán, J., En busca del unicornio, ob. cit., p. 20. En los bestiarios medievales la virgen siempre es figura clave en la persecución del animal, aunque varíen las formas en las que se consigue darle la muerte. Según muchas de las fuentes, cuando el unicornio reconoce a una doncella, se duerme a sus pies y así es posible matarlo. Según otras fuentes, la doncella amansa el animal y así puede conducirlo adonde quiere. Véase MalatXeverRía, I., Bestiario medieval, ob. cit., y Sebastián, Santiago (ed.), El Fisiólogo atribuido a San Epifanio y El Bestiario toscano, ob. cit.

63 Eslava Galán, J., En busca del unicornio, ob. cit., p. 21.

64 Eslava Galán, J., En busca del unicornio, ob. cit., p. 125.

65 Eslava Galán, J., En busca del unicornio, ob. cit., p. 178. 
protagonista se encuentra ante dos imágenes diferentes del mismo animal. El cuerno es la parte clave del cuerpo que evidencia el abismo entre lo que se esperaba ver y lo que se ve. A la visión preconcebida del unicornio, perteneciente al universo libresco y maravilloso, se contrapone la visión real del animal. De esta forma, lo que encuentra Olid no es el cuerno del unicornio «muy largo y blanco y retorcido y afilado», del que tanto ha oído hablar, sino un cuerno «corto y recio, de la forma del miembro del hombre, un poco curvo hacia arriba», que, como se puede imaginar, corresponde al rinoceronte (aunque tampoco se explicite la denominación de este otro animal exótico). Por lo tanto, esta descripción constituye un ejemplo perfecto de la tensión -propia del mundo medieval- entre la realidad tal y como es y la imagen libresca de esta realidad. Como comenta Bégelin: «Los viajeros-relatores emprenden su viaje esperando encontrar aquellos seres -descritos un sinfín de veces tanto en enciclopedias como en libros de viajes anteriores- y confrontan de continuo su saber libresco con lo que la realidad les presenta». ${ }^{66}$ La imagen del rinoceronte, frente a la visión del unicornio, es, así, un fiel reflejo de esta diferencia entre lo que ve el viajero-relator y lo que se suponía que iba a ver, del conflicto entre la realidad y la visión conceptualizada o imaginada de esta realidad. Frente a esta situación, el viajero en su relato se mantiene fiel a la realidad, la describe tal y como es, muestra su confusión, pero en ningún momento ajusta la imagen real a la visión imaginaria. Por esta razón, la descripción que ofrece es definitivamente la del rinoceronte y no del unicornio:

Y en sintiéndonos llegar, quizá porque nos oliera en el aire, el unicornio más grande, que más cerca de nosotros estaba, dejó de pacer la hierba y levantó un poco la enorme cabeza y movió las orejas, que las tenía cortas como de caballo, para donde nosotros veníamos y no se movió más. [...] Y mientras fui admirando el gran cuerpo que la bestia tenía, que era como de buey muy grande, y las patas cortas y muy recias y la cabeza enorme y pesada como de jabalí y por la parte del hocico tan grande como por la parte de los ojos. Y sobre el hocico aquel cuerno poderoso y otro cuernecillo más chico por encima de él. ${ }^{67}$

Como se puede observar, la descripción del animal regresa aquí al molde descriptivo medieval. De la misma forma que en los textos del Medievo examinados, también aquí la comparación es una herramienta clave para la construcción de la imagen del animal. La bestia que ve el protagonista tiene las orejas como las de caballo, su cuerpo recuerda el de un buey grande y su cabeza parece ser la de jabalí. De la misma forma que en los casos ya comentados, en esta descripción se recurre a los adjetivos que, por un lado, destacan la grandeza y la peligrosidad del rival al que se enfrenta el protagonista: la cabeza «enorme y pesada», «gran cuerpo», «cuerno

66 BéGuelin-Argimón, V., La geografía en los relatos de viajes castellanos del ocaso de la Edad Media. Análisis del discurso y léxico, Lausanne, Hispania-Helvética, 2011, p. 221.

67 Eslava Galán, J., En busca del unicornio, ob. cit., p. 178. 
poderoso», y por otro lado, describen aquellas partes del cuerpo que llaman la atención del relator: «patas cortas y muy recias», «cuernecillo más chico». También se observa la enumeración iterativa de diversos rasgos del animal a través del polisíndeton. Asimismo, de modo similar a otros animales exóticos, también este ser aparentemente increíble aparece adscrito al mundo de lo maravilloso: «Y era maravilla ver cómo los pasadores del lomo, donde más recio tenía el cuero, apenas le habían entrado medio palmo, como si hubiesen dado contra madera dura de olivo».68

Curiosamente, aunque el autor hace evidente al lector que el animal no se puede identificar con el unicornio, el protagonista no pone en duda que está ante el objetivo de su expedición y da por supuesto que se ha encontrado, finalmente, con el ambicionado unicornio. Por esta razón siempre se refiere a él con este nombre y cree que la forma de cazarlo será la misma que conoce por los tratados medievales: «Y nosotros pasamos adelante y la niña sudaba y temblaba de mis manos fuertemente cogida y yo la llevaba delante de mí para que el unicornio la ventease primero y se amansara a su olor». ${ }^{69}$ Esta fe ciega en la eficacia de los métodos de caza supuestamente descritos por Plinio, así como la justificación del fracaso por la idea de que la virgen fuera una muchacha negra -en vez de la típica doncella nívea del imaginario medieval- puede despertar en el lector contemporáneo una sensación tragicómica. Por un lado, es posible reírse de la ingenuidad del protagonista, pero por otro, lo absurdo de la escena, culminación de la infructuosa hazaña, infunde también un sentimiento de compasión por él y por el sinsentido de su recorrido. No obstante, junto a este efecto tragicómico, la novela le permite al lector entender mejor la compleja situación del viajero medieval, siempre desgarrado entre lo que ve y lo que se supone que iba a ver, entre las esperanzas depositadas en su viaje y la cruda realidad de esta experiencia.

\section{CONCLusiones}

Como se ha podido observar, la novela histórica, que por un lado puede aprovecharse para reproducir o imitar la peculiar retórica del relato medieval, pero por otro se ve impedida a alejarse de ella, por depender de los nuevos equilibrios de funcionamiento de la narrativa contemporánea, no solo opta por seguir muy fiel las descripciones medievales de animales exóticos, sino que también recurre a ellas -se diría que las necesita y busca- para alimentar la ambientación histórica y la tensión narrativa en el tejido argumental de sus textos. Mientras que en Embajada a Samarcanda el autor se limita a copiar casi literalmente las descripciones del original medieval, En busca del unicornio va más allá y junto a las descripciones medievalizantes de animales exóticos, valiéndose

68 Eslava Galán, J., En busca del unicornio, ob. cit., p. 179.

69 Eslava Galán, J., En busca del unicornio, ob. cit., p. 178. 
de las creencias medievales y de los tratados naturales de esta época, recurre a la figura del unicornio y construye en torno a él toda la trama de la novela. El análisis de este texto resulta especialmente interesante, ya que su autor aprovecha muy bien la premisa de que su obra no sea una crónica de hechos reales, sino una ficción literaria, para hablar del animal fabuloso que formaba parte de la cosmovisión medieval, lo que le permite acercar al lector contemporáneo el mundo medieval: acercarlo y tensionarlo; colocarlo en una posición no pasiva, sino incómoda o crítica. A través de la introducción de la figura del unicornio como nuevo animal exótico, confrontada con la de su equivalente real, el rinoceronte, Eslava Galán consigue reflejar la compleja situación del viajero medieval: el omnipresente conflicto entre las ideas imaginarias que debería confirmar en su viaje y la verdad que se aleja de las visiones de su época. Por tanto, en En busca del unicornio la descripción resulta esencial, ya que no solo pretende de manera superficial reproducir el estilo medieval a la hora de plasmar las realidades nuevas, ambientándolas con una convincente pátina de antigüedad, sino que pugna más profundamente por acercar al lector a la mentalidad de la época, a la forma de comprender el viaje, sus objetivos, su sentido, y le permite entender mejor al protagonista, sus dudas, su compromiso como servidor y el conflicto interior en el que se ve sumergido.

Como se ha podido ir comprobando, la descripción de los animales exóticos constituye en principio, formalmente, una suerte de puente que utilizan los autores de la novela histórica de viaje medieval para acercar sus obras al estilo de los textos medievales originales. Los escritores actuales que trabajan la novela histórica centrada en el viaje medieval recurren al modelo original de las descripciones en sus textos de referencia y las mimetizan casi literalmente en sus obras, con el fin de reproducir determinados aspectos llamativos de la poderosa poética de muchos relatos de viajes medievales. A través de la utilización de esas técnicas de descripción en las novelas históricas contemporáneas se refuerza la ambientación medieval. Pero, además, y no menos importante, con este procedimiento se pretende obligar al lector moderno a tomar una posición de lectura, produciendo efectos de identificación (con la poética del relato medieval) y a la vez distanciamiento (respecto a las formas narrativas actuales). De esta forma, la descripción del animal exótico se convierte en un instrumento esencial a la hora de construir un discurso medievalizante de la novela histórica.

\section{Bibliografía}

Alburquerque García, L., «"Relatos de viaje” y paradigmas culturales», en Letras, 71 (2015), pp. 63-76.

, «El "relato de viajes": hitos y formas en la evolución del género», en Revista de Literatura, 73 (2011), pp. 15-34. 
BéGuelin-Argimón, V., La geografía en los relatos de viajes castellanos del ocaso de la Edad Media. Análisis del discurso y léxico, Lausanne, Hispania-Helvética, 2011.

Beltrán Llavador, R., "Los libros de viajes medievales castellanos», en Revista de Filología Románica, anejo 1, 1991, pp. 121-164.

Eslava Galán, J., En busca del unicornio, Barcelona, Planeta, 1991.

[Pero Tafur] Andanças e viajes de un hidalgo español, Marcos Jiménez de la espada (ed.); estudio y descripción de Roma por José Vives Gatell; presentación bibliográfica de Francisco López Estrada, Barcelona, El Albir, 1982.

López Estrada, F. (ed.), Embajada a Tamorlán, Madrid, Castalia, 1999.

Libros de viajeros hispánicos medievales, Madrid, Ediciones del Laberinto, 2003.

Malaxecheverría, I., Bestiario medieval, Madrid, Siruela, 1986.

Martínez LaÍnEz, F., Embajada a Samarcanda, Barcelona, Belacqua, 2003.

Pérez Priego, M. Á., «Estudio literario de los libros de viajes medievales», en Epos: Revista de filología, 1, 1984, pp. 217-240.

Rubio Tovar, J., Libros españoles de viajes medievales:(Selección), Madrid, Taurus, 1986.

Schiltberger, J., Als Sklave im Osmanischen Reich und bei den Tataren, Ulrich Schlemmer (ed.), Stuttgart, Thienemann, 1983.

Sebastián, S., (ed.), El Fisiólogo atribuido a San Epifanio y El Bestiario toscano, Madrid, Tuero, 1986. 